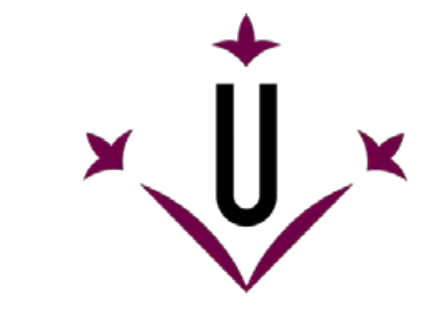

Universitat de Lleida

Document downloaded from:

http://hdl.handle.net/10459.1/62725

The final publication is available at:

https://doi.org/10.1021/acs.jafc.7b03049

Copyright

(c) American Chemical Society, 2017 
Article

\section{Chemical Composition and Water Permeability of Fruit and Leaf Cuticles of Olea europaea L.}

Hua Huang, Markus Burghardt, Ann-Christin Schuster, Jana Leide, Isabel Lara, and Markus Riederer J. Agric. Food Chem., Just Accepted Manuscript • DOI: 10.1021/acs.jafc.7b03049 • Publication Date (Web): 07 Sep 2017

Downloaded from http://pubs.acs.org on September 12, 2017

\section{Just Accepted}

"Just Accepted" manuscripts have been peer-reviewed and accepted for publication. They are posted online prior to technical editing, formatting for publication and author proofing. The American Chemical Society provides "Just Accepted" as a free service to the research community to expedite the dissemination of scientific material as soon as possible after acceptance. "Just Accepted" manuscripts appear in full in PDF format accompanied by an HTML abstract. "Just Accepted" manuscripts have been fully peer reviewed, but should not be considered the official version of record. They are accessible to all readers and citable by the Digital Object Identifier (DOI®). "Just Accepted" is an optional service offered to authors. Therefore, the "Just Accepted" Web site may not include all articles that will be published in the journal. After a manuscript is technically edited and formatted, it will be removed from the "Just Accepted" Web site and published as an ASAP article. Note that technical editing may introduce minor changes to the manuscript text and/or graphics which could affect content, and all legal disclaimers and ethical guidelines that apply to the journal pertain. ACS cannot be held responsible for errors or consequences arising from the use of information contained in these "Just Accepted" manuscripts. 
Title: Chemical Composition and Water Permeability of Fruit and Leaf Cuticles of Olea europaea L.

Authorship: Hua Huang ${ }^{1}$, Markus Burghardt ${ }^{1}$, Ann-Christin Schuster ${ }^{1}$, Jana Leide ${ }^{1}$, Isabel Lara $^{2}$, and Markus Riederer ${ }^{1, *}$

Institutional Affiliations: ${ }^{1}$ University of Würzburg, Julius von Sachs Institute of Biosciences, Germany, ${ }^{2}$ Department of Chemistry, Unitat de Postcollita-XaRTA, AGROTÈCNIO, Universitat de Lleida, Spain, ${ }^{*}$ Corresponding author

Corresponding Author: E-mail: riederer@uni-wuerzburg.de, Telephone number: +49 931 3186200

Manuscript Type: Research article 


\section{ABSTRACT}

2 The plant cuticle, protecting against uncontrolled water loss, covers olive (Olea europaea)

3 fruits and leaves. The present study describes the organ-specific chemical composition of the

4 cuticular waxes and the cutin and compares three developmental stages of fruits (green,

5 turning and black) with the leaf surface. Numerous organ-specific differences, such as the

6 total coverage of cutin monomeric components $\left(1034.4 \mu \mathrm{g} \mathrm{cm}^{-2}\right.$ and $\left.630.5 \mu \mathrm{g} \mathrm{cm}^{-2}\right)$ and the

7 cuticular waxes $\left(201.6 \mu \mathrm{g} \mathrm{cm}^{-2}\right.$ and $\left.320.4 \mu \mathrm{g} \mathrm{cm}^{-2}\right)$ among all three fruit stages and leaves,

8 respectively, were detected. Water permeability as the main cuticular function was five-fold

9 lower in adaxial leaf cuticles $\left(2.1 \times 10^{-5} \mathrm{~m} \mathrm{~s}^{-1}\right)$ in comparison to all three fruit stages $\left(9.5 \times 10^{-}\right.$

$10{ }^{5} \mathrm{~m} \mathrm{~s}^{-1}$ ). The three fruit developmental stages have the same cuticular water permeability. It is

11 hypothesized that a higher weighted average chain length of the acyclic cuticular components

12 leads to a considerably lower permeability of the leaf as compared to the fruit cuticle.

15 Key Words: average chain-length; cuticular transpiration, cutin, fruit, leaf, plant cuticle, 16 triterpenoids, very-long-chain acyclic components, wax 


\section{INTRODUCTION}

2 Olea europaea L. (Oleaceae) is an evergreen tree with silvery green, elongated leaves.

3 Producing small non-climacteric drupes, it is one of the predominant fruit tree crops in the

4 Mediterranean area and, thus, is of high economic importance. The total world production of

5 olive fruits has nearly doubled from 8.0 to 15.4 million tons during the past four decades

6 (1974 to 2014; FAOSTAT 2017, http, //www.fao.org/faostat/en/\#data/QC). About 58\% of the

7 crop is produced in Europe, mainly Spain, Italy, and Greece. Hundreds of olive cultivars are

8 documented, such as the economically important 'Arbequina' cultivar originating from Spain.

9 Plants growing in Mediterranean-type climates often suffer from various environmental

10 stresses, such as elevated temperatures, high vapor pressure deficits, and limited water

11 availability. ${ }^{1}$ The importance of protecting olive leaves and fruits from uncontrolled water

12 loss is given throughout the whole fruit developmental process, which includes fruit set,

13 growth, maturation and oil accumulation in the fruit pulp. ${ }^{2}$ During fruit growth, stomata lose

14 their shape and are covered by cuticular waxes. ${ }^{3,4}$ Trichomes and stomata are mainly

15 occurring on the abaxial leaf surface, very few incompletely degraded trichomes with

16 suberized stalks exist on the adaxial leaf surface..$^{5-7}$ Thus, the plant cuticle covering fruit and

17 leaf surfaces is the main barrier limiting uncontrolled water loss.

The plant cuticle is considered an important structure affecting olive fruit and leaf transpiration, especially under drought conditions. Water deficit induced an increase of fruit cuticle thickness when compared to olive fruits grown under normal irrigation. ${ }^{8,9}$ However, thicker plant cuticles do not provide more effective transpiration barriers. ${ }^{10,11}$ Plant cuticles are lipoid in nature consisting of a cutin matrix, a polyester of $\mathrm{C}_{16}$ and $\mathrm{C}_{18}$ fatty acids and hydroxy fatty acids, often with additional hydroxy, carboxy, epoxy and oxo groups in secondary mostly mid-chain position with cuticular waxes embedded within or deposited onto

25 its surface. ${ }^{12,13}$ The cuticular waxes form the main transport-limiting barrier. ${ }^{10,14}$ However, 
1 proposed that cutin and the corresponding ester-linkage might play a major role in

2 establishing barrier properties by providing the framework in which the cuticular waxes are 3 arranged. $^{15,16}$

4 The cuticular waxes from different cultivars and different developmental stages of olive fruits

5 and leaves are dominated by pentacyclic triterpenoids and additionally contain minor amounts

6 of very-long-chain fatty acid derivatives, the very-long-chain acyclic wax compounds. ${ }^{17-21} \mathrm{Up}$

7 to now, most of the information available is about the cuticular wax composition of olive

8 fruits while the leaf waxes have not been investigated to the same degree. Furthermore, there

9 is no study on the composition of the cutin polymer neither of olive fruits nor leaves.

During maturation, olive fruits having attained their final size change color turning from

11 green to black with an intermediate red-to-purple stage called the turning stage. The turning

12 stage is considered to be important for the tolerance and/or resistance to biotic and abiotic

13 environmental factors. ${ }^{21}$ However, the contribution of the cuticular components to cuticle

14 functions, particularly the transpiration barrier properties, have not been comprehensively

15 studied.

16 The present study aims at elucidating differential chemical compositions of the plant cuticle,

17 for the first time comparing fruit developmental stages (here green, turning and black stage)

18 with the leaf surface within one plant species. The cuticular waxes and the cutin monomeric

19 composition were used to determine the contribution of cuticular components to the 20 transpiration barrier properties. 


\section{MATERIALS AND METHODS}

\section{Plant Material}

3 Trees of Olea europaea L. cultivar 'Arbequina' (Oleaceae) were grown in El Soleràs, Lleida, 4 Spain $\left(41^{\circ} 24^{\prime} 48.71 " \mathrm{~N}, 0^{\circ} 40^{\prime} 50.05^{\prime \prime} \mathrm{E}\right)$. The trees were non-irrigated and only rain-fed. Fruit 5 samples at different development stages (green, turning and black) were harvested during the 6 ripening period in November 2014. Leaves and fruits were collected from the same trees

7 during the same ripening period. For the chemical analysis (monomeric cutin and cuticular 8 wax composition) five replicates were used. The permeability experiments were repeated with 912 fruits/leaves, respectively.

\section{Chemicals}

For cuticle isolation pectinase (Trenolin, Erbslöh, Geisenheim, Germany), cellulase (Celluclast, NCBE, University of Reading, UK), citric acid monohydrate (Applichem, Darmstadt, Germany) and sodium azide (Sigma-Aldrich, Steinheim, Germany) were used.

For extraction and analysis chloroform ( $\geq 99.8 \%$ ), pyridine, sodium chloride and sodium sulfate were purchased from Roth (Karlsruhe, Germany). Boron trifluoride in methanol (1.3 M) was obtained from Fluka (Neu-Ulm, Germany). $N$-tetracosane and $n$-dotriacontane were provided by Sigma-Aldrich (Steinheim, Germany). N,O-bis(trimethylsilyl) trifluoroacetamide was from Macherey-Nagel (Düren, Germany).

Authentic standards of ß-amyrin, erythrodiol, ursolic acid and betulinic acid were purchased from Roth (Karlsruhe, Germany), oleanolic acid from Sigma-Aldrich (Steinheim, Germany).

\section{Cutin Depolymerization for Chemical Analysis}

Cuticular membranes from both fruits and adaxial leaf surfaces were isolated enzymatically in citric acid buffer containing pectinase (1\%), cellulase (1\%) and $1 \mathrm{mM}$ sodium azide to avoid growth of microorganism. ${ }^{22}$

For the cutin analysis, the air-dried isolated cuticular membranes were immersed in chloroform to remove the cuticular waxes. The wax-free polymer matrix was depolymerized 
1 with boron trifluoride in methanol $(1.3 \mathrm{M})$ at $70^{\circ} \mathrm{C}$ for $16 \mathrm{~h} . \mathrm{N}$-dotriacontane as an internal

2 standard was added. Subsequently, a saturated aqueous sodium chloride solution was added.

3 The mixture was extracted three times with chloroform. The collected extracts were dried

4 over sodium sulfate, and the organic solvent was gently evaporated under a continuous flow

5 of nitrogen.

\section{Cuticular Wax Extraction for Chemical Analysis}

7 To extract the cuticular waxes from the fruit surface, whole fruits were dipped in chloroform.

8 To avoid contact of the solvent with the pedicel, approximately $90 \%$ of the fruit was vertically

9 dipped into chloroform for $60 \mathrm{~s}$. The cuticular wax from the adaxial leaf surface was extracted by dipping the enzymatically isolated adaxial cuticle two subsequent times in chloroform. Each fruit sample was extracted three times consecutively. $N$-tetracosane was added to the extracts as an internal standard. The solvent was evaporated under a gentle stream of nitrogen gas until dryness.

\section{Chemical Analysis of Cuticular Components}

Prior to the gas chromatographic analysis, the cuticular wax and cutin samples were derivatized with $\mathrm{N}, \mathrm{O}$-bis(trimethylsilyl) trifluoroacetamide in pyridine for $30 \mathrm{~min}$ at $70^{\circ} \mathrm{C}$. For the quantitation of the compounds, a capillary gas chromatograph with flame ionization detector (6850N, GC-System; Agilent Technologies, Santa Clara, California) and on-column injection with a capillary column $(30 \mathrm{~m} \times 0.32 \mathrm{~mm}$, DB-1 ms, $0.1 \mu \mathrm{m}$ film; J\&W Scientific, Agilent Technologies) was used. For separation of the cuticular wax compounds, the samples were injected at $50^{\circ} \mathrm{C}$ followed by $2 \mathrm{~min}$ at $50^{\circ} \mathrm{C}$, temperature raised by $40^{\circ} \mathrm{C} \mathrm{min}^{-1}$ to $200^{\circ} \mathrm{C}$, held for $2 \mathrm{~min}$ at $200^{\circ} \mathrm{C}$, raised by $3{ }^{\circ} \mathrm{C} \min ^{-1}$ to $320^{\circ} \mathrm{C}$ and held for $30 \mathrm{~min}$ at $320^{\circ} \mathrm{C}$. For separation of the cutin monomers, samples were injected at $50^{\circ} \mathrm{C}$, followed by $1 \mathrm{~min}$ at $50^{\circ} \mathrm{C}$, temperature raised by $10^{\circ} \mathrm{C} \min ^{-1}$ to $150^{\circ} \mathrm{C}$, held for 2 min at $150^{\circ} \mathrm{C}$, raised by $3^{\circ} \mathrm{C} \mathrm{min}^{-1}$ to $320^{\circ} \mathrm{C}$ and held for $30 \mathrm{~min}$ at $320^{\circ} \mathrm{C}$. 
1 Qualitative analysis was carried out with a gas chromatograph (6890N, Agilent Technologies)

2 equipped with a mass spectrometric detector ( $\mathrm{m} / \mathrm{z}$ 50-750, MSD 5973; Agilent Technologies)

3 under the same gas chromatographic conditions except that helium was used as carrier gas.

4 Identification of the compounds was carried out by their mass spectra using authentic

5 standards, the Wiley $10^{\text {th }}$ /NIST 2014 mass spectral library (W10N14; John Wiley \& Sons,

6 Hoboken, New Jersey) or by interpretation of the spectra, by their retention times and/or by

7 comparison with literature data. Based on the coverage of very-long-chain acyclic wax

8 compounds and their carbon chain length distribution, the weighted average chain length

9 (ACL) of very-long-chain acyclic wax components was calculated. ACL is the weight10 averaged number of carbon atoms, defined as:

$$
\mathrm{ACL}=\frac{\sum\left(\mathrm{C}_{\mathrm{n}} \times \mathrm{n}\right)}{\sum \mathrm{C}_{\mathrm{n}}}
$$

with $C_{n}$ being the coverage of each very-long-chain acyclic wax compound with $n$ carbon atoms.

\section{Determination of Cuticular Transpiration}

The transpiration from whole fruits and leaves was determined gravimetrically by measuring the water loss over time. Before measurement, the attachment site of the fruit pedicel and the leaf petioles were sealed with paraffin wax (melting point $65^{\circ} \mathrm{C}$; Roth, Karlsruhe, Germany). The abaxial leaf surface was sealed with paraffin wax to ensure that the water transpiration occurs only via the stomata-free adaxial leaf surface. The fruit and leaf samples were placed in boxes over silica gel (Applichem, Darmstadt, Germany) to reduce the relative humidity to nearly zero. The boxes were placed in an incubator (IPP 110, Memmert, Schwabach, Germany) to control the surrounding temperature $\left(25^{\circ} \mathrm{C}\right)$. The amount of water transpired from whole fruit and adaxial leaf surfaces versus time (five to six data points per individual sample) was measured using an analytic electronic balance with a precision of $0.1 \mathrm{mg}$ (MC-1 AC210S, Sartorius, Göttingen, Germany). The temperature in the incubator was controlled 
1 with a digital thermometer (Testoterm 6010, Lenzkirch, Germany), and the actual temperature

2 of fruit and leaf surfaces was measured by an infrared laser thermometer (Harbor Freight

3 Tools, Calabasas, California). The transpiration rate (flux of water vapor; $\mathrm{J}$ in $\mathrm{g} \mathrm{m}^{-2} \mathrm{~s}^{-1}$ ) was

4 obtained from the change of the fresh weight of the samples ( $\Delta \mathrm{W}$ in $\mathrm{g})$ over time $(\Delta \mathrm{t}$ in $\mathrm{s})$ and

5 surface area $\left(\mathrm{A}\right.$ in $\left.\mathrm{m}^{2}\right)$ :

$$
\mathrm{J}=\frac{\Delta \mathrm{W}}{\Delta \mathrm{t} \cdot \mathrm{A}}
$$

7 The form of the fruit of the olive cultivar used in this study deviates only slightly from a 8 perfect sphere. So the fruit surface area $\left(\mathrm{A}_{\text {fruit }}\right)$ was calculated for a sphere with a radius 9 calculated as the mean of the polar and equatorial radii of the fruit. The leaf surface area $\left(\mathrm{A}_{\text {leaf }}\right)$ of the adaxial surface was obtained by scanning the leaf surface. The permeance $\left(\mathrm{P}\right.$ in $\left.\mathrm{m} \mathrm{s}^{-1}\right)$ was calculated from the transpiration rate $(\mathrm{J})$ divided by the driving force:

$$
\mathrm{P}=\frac{\mathrm{J}}{\mathrm{c}_{\mathrm{wV}}^{*}\left(\mathrm{a}_{\text {fruit }} / \mathrm{leaf}^{\left.-\mathrm{a}_{\text {air }}\right)}\right.}
$$

The water vapor saturation concentration at the actual fruit or leaf temperature (water vapor content of air at saturation; $\left.\mathrm{c}^{*}{ }_{\mathrm{wv}}\right)$ was obtained from tabulated values. ${ }^{23}$ Air water activity $\left(\mathrm{a}_{\text {air }}\right)$ over silica gel was close to zero. The water activity in the fruit or leaf ( $\left.a_{\text {fruit/leaf }}\right)$ was assumed to be unity. ${ }^{24}$

\section{Statistical Analysis}

Statistical analyses were performed using SigmaPlot 13 (Systat Software GmbH, Erkrath, Germany). The total amount of cutin monomers, total wax amount, surface area and cuticular permeance were checked for normal distribution by the Shapiro-Wilk normality test ( $\mathrm{p}$-value to reject 0.05 ). Normally distributed data are given as means with the corresponding standard deviations. Comparisons between leaf parameters and black-stage fruit parameters were tested for significance with Student's t-test (level of significance $p<0.05$ ) and, when comparing the different fruit stages, Kruskal-Wallis one way analysis of variance (ANOVA). 


\section{RESULTS}

\section{Composition of the Cutin Polymer of Olea europaea Fruits and Leaves}

3 During fruit development, the quantity, as well as the quality of the cutin matrix covering

4 olive fruits, changed. The amount of cutin monomers was $969 \mu \mathrm{g} \mathrm{cm}^{-2}, 1005 \mu \mathrm{g} \mathrm{cm}^{-2}$ and

$51129 \mu \mathrm{g} \mathrm{cm}^{-2}$ in green, turning and black fruits, respectively, with no significant differences

6 among these values (Table 1; Figure 1A). This trend during fruit development resulted mainly

7 from an accumulation of fatty acids, $\omega$-hydroxy fatty acids and $\omega$-hydroxy fatty acids with

8 mid-chain hydroxy groups.

9 In comparison to fruits, the total amount of cutin monomers of the fully expanded, adaxial 10 leaf surface was $35 \%$ to $44 \%$ lower $\left(631 \mu \mathrm{g} \mathrm{cm}^{-2}\right)$. In the fruit cutin matrix, the predominant cutin monomers were $\omega$-hydroxy fatty acids with mid-chain hydroxy groups ( $72 \%$ to $77 \%$ of the total cutin). The main cutin compounds were 9/10,16-dihydroxyhexadecanoic acid (33\% to $35 \%), 9,10,18$-trihydroxyoctadecenoic acid $(14 \%$ to $26 \%)$ and $9,10,18$ trihydroxyoctadecanoic acid (13\% to $17 \%)$. Similarly, the major cutin monomers on the adaxial leaf surface were $\omega$-hydroxy fatty acids with mid-chain hydroxy groups $(43 \%$ of the total cutin) dominated by 9/10,16-dihydroxyhexadecanoic acid (26\%) and 9,10,18trihydroxyoctadecanoic acid (16\%). The $\omega$-hydroxy fatty acid with a mid-chain epoxy group (9,10-epoxy-18-hydroxyoctadecanoic acid, $39 \%$ of the total cutin) was only detected in the leaf cutin matrix. Small amounts of unsubstituted fatty acids with even-numbered carbon chain lengths from $\mathrm{C}_{16}$ to $\mathrm{C}_{28}$ ( $2 \%$ to $3 \%$ of the total cutin), $\omega$-hydroxy fatty acids ( $2 \%$ to $9 \%$ ), $\alpha, \omega$-dicarboxylic fatty acids with mid-chain epoxy group $(1 \%)$ and phenolic compounds $(<1 \%$ to $5 \%$ ) were also found in the cutin matrix of fruit and leaf surfaces. $\omega$-Hydroxy fatty acids with a mid-chain oxo group (1\%) and $\alpha, \omega$-dicarboxylic fatty acids $(<1 \%)$ were identified exclusively in the fruit cutin matrix.

The degree of unsaturation of the cutin polymer was $18 \%$ to $32 \%$ in green, turning, and black fruits, and $2 \%$ in the leaf but the degree of epoxidation was higher for the leaf $(40 \%)$ as 
1 compared to the fruit cutin (1\%). Furthermore, the ratio of the main cutin monomers with a

2 carbon chain length of $\mathrm{C}_{16}$ and $\mathrm{C}_{18}$ shifted from 1.0 to 0.8 in green, turning and black fruits,

3 and amounted to 0.5 in the leaf cutin matrix (Table 3 ).

\section{Composition of the Cuticular Wax of Olea europaea Fruits and Leaves}

5 The cuticular wax compositions and amounts of olive fruits at different developmental stages

6 and the adaxial leaf surface was determined. The total cuticular wax coverage did not change

7 significantly from green to turning to black fruits $\left(195,202\right.$ and $209 \mu \mathrm{g} \mathrm{cm}^{-2}$, respectively;

8 Table 2; Figure 1B). Compared to the fruit waxes, the wax coverage of the adaxial leaf

$9 \quad$ surface was significantly higher $\left(320 \mu \mathrm{g} \mathrm{cm}^{-2}\right)$.

Significant amounts of pentacyclic triterpenoids were present in the cuticular waxes of fruits, which did not change significantly over the three developmental stages investigated (Table 3 ). At the same time, the very-long-chain acyclic coverage significantly increased from 39 (green) to $62 \mu \mathrm{g} \mathrm{cm}^{-2}$ (black; Table 3) leading to a decrease in the relative contribution of triterpenoids to the total wax from $74 \%$ (green), $67 \%$ (turning) to $62 \%$ black. The leaf cuticular waxes consisted to an even higher degree of triterpenoids $(83 \%)$ with a coverage of $266 \mu \mathrm{g} \mathrm{cm}^{-2}$; Table 3). The cyclic wax fraction consists of the triterpenoid acids oleanolic acid, maslinic acid, ursolic acid, betulinic acid, and the triterpenoid alcohols $\beta$-amyrin, erythrodiol, and uvaol. The major triterpenoid was oleanolic acid (35\% to $37 \%$ in fruits, $60 \%$ in leaves). Additionally, an oleanolic acid derivative (11\% to $20 \%)$ and maslinic acid (10\% to $14 \%)$ were found to be highly abundant in the cuticular fruit waxes. In comparison to fruits, higher amounts of erythrodiol (6\%), uvaol (7\%) and ursolic acid (9\%) were found on the adaxial leaf surface (Table 2). Ursolic acid was not identified in olive fruits and the oleanolic acid derivative and betulinic acid not in olive leaves.

Compared to the high amounts of pentacyclic triterpenoids, smaller proportions of very-longchain acyclic wax compounds were detected (Table 3). The main component classes were fatty acids $(8 \%$ to $9 \%)$ and primary alcohols $(9 \%$ to $11 \%)$ in fruit cuticular waxes, most 
1 prominently hexacosanoic acid $\left(\mathrm{C}_{26}\right)$ and hexacosanol $\left(\mathrm{C}_{26}\right)$. In leaf cuticular waxes, fatty 2 acids (1\%) and $n$-alkanes $(3 \%)$ were dominated by octacosanoic acid $\left(\mathrm{C}_{28}\right), n$-hentriacontane $3\left(\mathrm{C}_{31}\right)$ and $n$-tritriacontane $\left(\mathrm{C}_{33}\right)$. Minor proportions of aldehydes, $n$-alkanes, alkyl esters, 4 methyl esters, phenyl methyl esters, diacylglycerols, and sterols were also found in the fruit 5 cuticular wax mixture $(<1 \%$ to $4 \%)$. Aldehydes, alkyl esters, methyl esters, phenyl methyl 6 esters, diacylglycerols, and sterols were not identified in cuticular waxes of the adaxial leaf 7 surface. Only small amounts of primary alcohols $(<1 \%)$ were found.

8 The homologous series of fatty acids, primary alcohols, aldehydes, alkyl esters, methyl esters 9 and phenyl methyl esters showed a very pronounced even-numbered carbon chain length distribution, while odd-numbered homologs dominated the distributions of $n$-alkanes and diacylglycerols. The carbon chain length distribution of both fatty acids and primary alcohols ranged from $\mathrm{C}_{20}$ to $\mathrm{C}_{30}$ in all three fruit developmental stages. Aldehydes were identified from $C_{22}$ to $C_{30}$ in fruit cuticular waxes. These compound classes made up $92 \%$ of the total verylong-chain acyclic wax fraction in green, $83 \%$ in turning and $74 \%$ in black fruits. In contrast to fruit waxes, $n$-alkanes with odd-numbered carbon chain lengths primarily from $\mathrm{C}_{27}$ to $\mathrm{C}_{33}$ were the main very-long-chain acyclic wax compounds of the total very-long-chain acyclic wax fraction on the adaxial leaf surface (78\%). Fatty acids in adaxial leaf waxes ranged from $\mathrm{C}_{20}$ to $\mathrm{C}_{28}$, while the fraction of the primary alcohols contained only small amounts of hexacosanol $\left(\mathrm{C}_{26}\right)$ and octacosanol $\left(\mathrm{C}_{28}\right)$. The average chain length $(\mathrm{ACL})$ of very-long-chain acyclic wax compounds was 25.8 for green, 26.6 for turning and 27.3 for black fruits and 30.1 for the adaxial leaf surface (Table 3). The ratios of cuticular wax and cutin coverages were in the range of 0.2 for all three developmental stages of fruits and 0.52 for leaves (Table 3 ).

\section{Cuticular Water Permeability of Olea europaea Fruits and Leaves}

The fruit surface area was determined for relating the water loss to the transpiring area. It increased significantly by $28 \%$ from $4.6 \mathrm{~cm}^{2}$ in green to $6.1 \mathrm{~cm}^{2}$ in turning and $6.4 \mathrm{~cm}^{2}$ in black fruits (Figure 2A). The cuticular transpiration of astomatous fruit and adaxial leaf 
1 surfaces was determined gravimetrically. For both fruits and leaf, the cuticular water loss

2 followed a linear time course. The cuticular water loss of fruits at the three considered 3 developmental stages (green, turning and black) showed no significant differences but it was

4 considerably higher than the water loss rate across the adaxial leaf surface. Based on the

5 driving force, the cuticular water permeance was calculated. The cuticular water permeances

6 of green, turning and black fruits exhibited no significant differences and were on the average

$7 \quad 9.5 \times 10^{-5} \mathrm{~m} \mathrm{~s}^{-1}$ (Figure 2B). The cuticular water permeance of the adaxial leaf surface was 2.1

$8 \times 10^{-5} \mathrm{~m} \mathrm{~s}^{-1}$ and, thus, was significantly lower by a factor of five than that of the fruits.

9

\section{DISCUSSION}

The predominant cutin monomers of olive fruits in all three developmental stages are $\mathrm{C}_{16}$ and $\mathrm{C}_{18}$ type monomers, which were dominated by $9 / 10, \omega$-dihydroxyhexadecanoic acid similarly as in many other fruit crops such as Prunus avium L. (drupe $)^{25}$, Rubus chamaemorus L. (aggregate fruit with drupelets) $^{26}$, Capsicum annum L. (berry) ${ }^{27}$ and Solanum lycopersicum L. (berry). ${ }^{28}$ Overall, the amounts of cutin monomers from the green to the turning and black stage did not change significantly. A shift to a higher amount of $\mathrm{C}_{18}$ type monomers e.g. octadecenoic acid, $\omega$-hydroxyoctadecenoic acid and 9,10, $\omega$-trihydroxyoctadecenoic acid, resulting in an alteration of the $\mathrm{C}_{16} / \mathrm{C}_{18}$ ratio from 1.1 to 0.8 during fruit development, was detected. Kosma et al. $^{29}$ showed an increase in total cutin monomers for Solanum lycopersicum L. during fruit development. In contrast, a decrease of total cutin was detected during the final ripening of Prunus avium L. fruits. ${ }^{25}$

In comparison to the black-stage fruit, the adaxial leaf surface had a significantly smaller amount of cutin monomers. The prominent 9,10-epoxy- $\omega$-hydroxyoctadecanoic acid found in the olive leaf cutin had also been detected in leaves of Agave americana L., Clivia miniata (Lindl.) Bosse, Ilex aquifolium L., Nerium oleander L. and Sansevieria trifasciata Prain (evergreen leaves) ${ }^{30,31}$ and was not present in the olive fruits. Furthermore, the phenolic cutin 
1 fraction exclusively consisting of coumaric acid and derivatives was distinctly reduced in the

2 cutin matrix of olive leaves. The ratio between the long-chain acyclic and the phenolic cutin

3 proportions was 23.7 for black fruits but 215.4 for fully expanded leaves.

4 The ratio of $\mathrm{C}_{16} / \mathrm{C}_{18}$ cutin monomers was 0.5 for the leaf cutin and 0.8 for the black fruit cutin.

5 The leaf and fruit cutin of olive displayed a mixed $\mathrm{C}_{16}$ and $\mathrm{C}_{18}$ type, which is very common in

6 plants, e.g. in Ilex aquifolium L.. ${ }^{32}$ The fruit cutin matrix was also characterized by a

7 substantial proportion of unsaturated cutin monomers. The compositional differences between

8 fruit and leaf cutin of olive (carbon chain lengths, the degree of unsaturation, and the extent of

9 epoxidation) may lead to unique polymeric structures in both organs.

The cuticular waxes from the olive fruit surface of three developmental stages were dominated by pentacyclic triterpenoids. Triterpenoid coverage did not significantly change during fruit development. A decrease of triterpenoids in developing fruits was reported for Prunus avium L.. ${ }^{25}$ The very-long-chain acyclic components, mainly fatty acids and primary alcohols, constituted the smaller portion of cuticular waxes. An increase of the very-longchain acyclic fraction during fruit development was primarily due to a higher accumulation of alkyl esters and primary alcohols. Bianchi et al. ${ }^{17}$ compared the green and black developmental stages of fruits of the 'Coratina' cultivar. Similarly as found for the cultivar 'Arbequina,' the black-stage fruits exhibit a higher percentage of very-long-chain acyclic components compared to the green-stage fruit. Also in the case of the 'Coratina' cultivar, the fraction of pentacyclic triterpenoids decreased from the green to the black stage.

Overall, the total amount of cuticular waxes covering olive fruits was more or less constant at the green, turning and black stages, which comprise the late fruit expansion phase. For Solanum lycopersicum L. and Prunus avium L., a slight decrease of the cuticular wax quantity during the later fruit developmental stages was shown. ${ }^{25,28}$ This reduction of cuticular waxes was described as not a mere dilution effect, which could be due to the surface area expansion, but resulted from specific changes of individual constituents. ${ }^{25}$ 
1 Oleanolic acid was the major cuticular wax component in olive fruits over all three

2 developmental stages. As for olive fruits, this triterpene acid was also found as the main 3 triterpenoid in other fruit crops, e.g., Prunus domestica L. (drupe) ${ }^{33}$, Vaccinium myrtillus L.

4 (berry) $)^{34}$ and Vitis vinifera L. (berry). ${ }^{35-37}$ Fatty acids and primary alcohols with carbon chain

5 lengths between $\mathrm{C}_{20}$ and $\mathrm{C}_{30}$ were the most pronounced very-long-chain acyclic wax

6 compound classes in olive fruits. The very-long-chain acyclic wax fraction showed a

7 continuous increase in the average chain length (ACL), which describes the average number

8 of carbon atoms of very-long-chain acyclic components ${ }^{38}$, from 25.8 to 27.3 over the three

9 developmental stages. The ACL value is widely accepted as a proxy indicator for the cuticular 10 wax quality in plants.

Comparing the black-stage fruit with the adaxial leaf surface, the total cuticular wax amount

was significantly higher for the leaf surface than for the fruit surface. The leaf cuticular waxes were mainly composed of pentacyclic triterpenoids and a smaller fraction of very-long-chain acyclic components. Like in fruits, oleanolic acid was the major cuticular wax compound in leaves, which is not common for leaf cuticular waxes. ${ }^{39}$ In leaves of Ligustrum vulgare L., also a member of the Oleaceae plant family, ursolic acid dominated the cuticular wax mixture. $^{40}$

Fruits and leaves of olive were characterized by an organ-specific pattern of triterpenoid composition, which might indicate differences in the triterpenoid biosynthesis in both organs. Cuticular waxes of olive contained mainly pentacyclic triterpenoids from the oleanane type: predominantly oleanolic acid and maslinic acid in fruits and oleanolic acid and erythrodiol in leaves. With the exception of the deposition on the olive fruit surface, maslinic acid has been very rarely detected in fruits, e.g. in Ziziphus jujuba Mill. (drupe) ${ }^{41}$, Rubus chingii $\mathrm{Hu}$ (aggregate fruit with drupelets) ${ }^{42}$ and Malus pumila Mill. (pome) ${ }^{43}$. Additionally, cuticular waxes of olive leaves exhibited a high amount of ursolic acid and uvaol that belong to the 
1 ursane type of triterpenoids, whereas only fruit cuticular waxes had betulinic acid of the 2 lupane type. ${ }^{44}$

3 The ratio between the very-long-chain acyclic and the cyclic wax proportions was 0.5 for 4 black fruits and only 0.04 for fully expanded leaves. The very-long-chain acyclic wax fraction 5 of olive leaves exhibited a considerably higher average chain length (ACL) value of 30.1. N6 alkanes and fatty acids with carbon chain lengths between $\mathrm{C}_{26}$ and $\mathrm{C}_{33}$ as well as $\mathrm{C}_{20}$ and $\mathrm{C}_{30}$ 7 were the prominent very-long-chain acyclic wax compound classes in the cuticular waxes of 8 olive leaves. Bianchi et al. ${ }^{18}$ analyzed the leaf cuticular waxes of the olive cultivars 9 'Cipressino' and 'Coratina'. They also found that the main proportion were triterpenoids, and that the very-long-chain acyclic fraction was mainly composed of $n$-alkanes and fatty acids.

Similar very-long-chain acyclic component classes were detected for the 'Arbequina' cultivar, but the percentage of individual component classes might be cultivar-specific.

Olive fruits and leaves were characterized by a high amount of cuticular waxes but significant organ-specific modifications in both the very-long-chain acyclic wax compound classes and triterpene types, which might have a major influence on the barrier properties of the olive leaf and fruit surface. The total amounts and composition of the cuticles of olive fruits and leaves were different, also showing a different ratio between cuticular waxes and cutin monomers ( 0.2 for black fruits and 0.5 for fully expanded leaves), which may have an impact on the cuticular functions.

The cuticular water permeability of the three developmental fruit stages was not significantly different and was on the average $9.5 \times 10^{-5} \mathrm{~m} \mathrm{~s}^{-1}$. The increasing coverage of very-long-chain acyclic compounds from 39 (green) to $62 \mu \mathrm{g} \mathrm{cm}^{-2}$ (black) did not lead to changes in cuticular permeability.

The adaxial leaf surface of the 'Arbequina' cultivar had a cuticular permeance of $2.1 \times 10^{-5} \mathrm{~m}$ $\mathrm{s}^{-1}$ which is significantly lower by a factor of five than the water permeability of the blackstage fruits. Cuticular water permeances of leaves within the Oleaceae reported so far ranged 
1 from $1.5 \times 10^{-5} \mathrm{~m} \mathrm{~s}^{-1}$ to $1.9 \times 10^{-5} \mathrm{~m} \mathrm{~s}^{-1}$ measured for Ligustrum vulgare L., Forsythia

2 suspensa (Thunb.) Vahl and Syringa vulgaris L.. ${ }^{45,46}$ Schreiber and Riederer ${ }^{45}$ determined a

3 value of $5.5 \times 10^{-6} \mathrm{~m} \mathrm{~s}^{-1}$ for isolated leaf cuticles from an unspecified olive cultivar, which

4 was distinctly lower than that found for the 'Arbequina' cultivar in this study. A study

5 comparing leaves and fruits of several species showed that fruits generally had higher

6 cuticular permeabilities than leaves. ${ }^{45}$ Up to now, there was no study directly comparing the

7 cuticular permeability of fruits and leaves of the same species.

8 Alterations in cuticle composition are commonly proposed to affect the cuticular transport

9 barrier. Within the plant cuticle, the cuticular waxes establish the main transport-limiting barrier. Differences in the cutin polymer composition and the corresponding primary and secondary ester linkages have also been proposed to influence the barrier properties. ${ }^{15,16,47}$ The transpiration barrier properties of the cuticular waxes are associated with the very-longchain acyclic wax components rather than with the cyclic wax compounds. ${ }^{28,48,49}$ A model of the physical arrangement of the wax constituents suggests that very-long-chain acyclic components are arranged in impermeable crystalline domains and amorphous zones in between which may also contain cyclic components. ${ }^{14,50}$ Water diffusion is assumed to occur only in the amorphous zone following a very tortuous pathway around the crystalline flakes. Therefore, it has been proposed that the physical properties derived from wax composition and not wax quantity determine the efficacy of the transpiration barrier. ${ }^{10,14}$ In analogy to polyethylene, which is a semi-crystalline long-chain acyclic material comparable to cuticular waxes, the degree of crystallinity should determine the barrier properties of cuticular waxes. The higher the crystallinity is, the longer is the effective pathway, and consequently, the lower 23 is the effective diffusion coefficient of water molecules across this barrier. ${ }^{51}$ The average chain length (ACL) of the very-long-chain acyclic wax components is one of several parameters influencing crystallinity. 
1 In olive, the coverage of very-long-chain acyclic components in the cuticular waxes is almost

2 6-fold lower in leaves than in black-stage fruits.At the same time leaves have a two-fold

3 higher coverage of cyclic components. So, at first sight, one might expect that the fruits

4 should have a lower cuticular permeability since it has been shown in the past that the very-

5 long-chain acyclic components primarily make up the transpiration barrier while the

6 contribution of the cyclic components to the barrier is small or absent. Therefore, the reason

7 for the observed higher efficacy of the leaf transpiration barrier might be caused by

8 differences in the molecular properties of the very-long-chain fraction. We hypothesize that

9 the higher ACL in leaves as compared to fruits might be a prominent factor leading to the considerably lower permeability of the leaf cuticle. Additional factors like cutin polymer structure and cutin/wax interactions may also contribute to the organ-specific differences in cuticular permeability observed in this study.

\section{Funding Sources}

This project was supported by an Oversea Study Program of Guangzhou Elite Project (GEP, Approval No. Sui Jiaoke [2013]94) to HH and by a Chinese Academy of Sciences Visiting Professorship for Senior International Scientists grant no. 2011T2S31 to MR.

\section{ASSOCIATED CONTENT}

\section{Supporting Information}

Table S1. Detailed chemical composition of the cutin polymer of Olea europaea L. cultivar 'Arbequina' fruits in green, turning and black stages and the fully expanded, adaxial leaf surface. Data were given as means \pm standard deviation in $\mu \mathrm{g} \mathrm{cm}^{-2}(\mathrm{n}=5)$.

Table S2. Detailed chemical composition of the cuticular waxes of Olea europaea L. cultivar 'Arbequina' fruits in green, turning and black stages and the fully expanded adaxial leaf surface. Data were given as means \pm standard deviation in $\mu \mathrm{g} \mathrm{cm}^{-2}(\mathrm{n}=5)$. 


\section{REFERENCES}

(1) Connor, D.; Fereres, E. The physiology of adaptation and yield expression in olive. Hort. Rev. 2005, 31, 155-229.

(2) Gucci, R.; Goldhamer, D.; Fereres, E. Olive. In Crop yield response to water. Steduto, P.; Hsiao, T. C.; Fereres, E.; Raes, D., Eds., FAO Irrigation and Drainage Paper, Rome, 2012, pp 300-313.

(3) Proietti, P.; Famiani, F.; Tombesi, A. Gas exchange in olive fruit. Photosynthetica 1999, $36,423-432$.

(4) Lanza, B.; Di Serio, M. G. SEM characterization of olive (Olea europaea L.) fruit epicuticular waxes and epicarp. Sci.Hortic. 2015, 191, 49-56.

(5) Fahn, A. Structural and functional properties of trichomes of xeromorphic leaves. Ann. Bot. 1986, 57, 631-637.

(6) Bosabalidis, A. M.; Kofidis, G. Comparative effects of drought stress on leaf anatomy of two olive cultivars. Plant Sci. 2002, 163, 375-379.

(7) Ennajeh, M.; Vadel, A.; Cochard, H.; Khemira, H. Comparative impacts of water stress on the leaf anatomy of a drought-resistant and a drought-sensitive olive cultivar. J. Hortic. Sci. Biotechnol. 2010, 85, 289-294.

(8) Patumi, M.; d'Andria, R.; Marsilio, V.; Fontanazza, G.; Morelli, G.; Lanza, B. Olive and olive oil quality after intensive monocone olive growing (Olea europaea L., cv. Kalamata) in different irrigation regimes. Eood Chem. 2002, 77, 27-34.

(9) Gómez-del-Campo, M.; Pérez-Expósito, M. Á.; Hammami, S. B. M.; Centeno, A.; Rapoport, H. F. Effect of varied summer deficit irrigation on components of olive fruit growth and development. Agric. Water Manag. 2014, 137, 84-91.

(10) Riederer, M.; Schreiber, L. Protecting against water loss: analysis of the barrier properties of plant cuticles. J.Exp. Bot. 2001, 52, 2023-2032. 
(11) Bacelar, E. A. Sclerophylly and leaf anatomical traits of five field-grown olive cultivars growing under drought conditions. Tree Phvsiol. 2004, 24, 233-239.

(12) Pollard, M.; Beisson, F.; Li, Y.; Ohlrogge, J. B. Building lipid barriers: biosynthesis of cutin and suberin. Trends Plant Sci. 2008, 13, 236-246.

(13) Yeats, T. H.; Rose, J. K. The formation and function of plant cuticles. Plant Physiol. $\mathbf{2 0 1 3}, 163,5-20$.

(14) Riederer, M.; Schreiber, L. Waxes: the transport barriers of plant cuticles. In Waxes. Chemistry, molecular biology and functions. Hamilton, R. J., Ed., The Oily Press, Dundee, Scotland, 1995, pp 131-156.

(15) Goodwin, S. M.; Jenks, M. A. Plant cuticle function as a barrier to water loss. In Plant abiotic stress. Jenks, M. A.; Hasegawa, P. M., Eds., Blackwell Publishing, Oxford, UK, 2005, pp 14-36.

(16) Kosma, D. K.; Jenks, M. A. Eco-physiological and molecular-genetic determinants of plant cuticle function in drought and salt stress tolerance. In Advances in molecular breeding toward drought and salt tolerant crops. Jenks, M. A.; Hasegawa, P. M.; Jain, S. M., Eds., Springer, Dordrecht, Netherlands, 2007, pp 91-210.

(17) Bianchi, G.; Murelli, C.; Vlahov, G. Surface waxes from olive fruits. Phytochemistry 1992, 31, 3503-3506.

(18) Bianchi, G.; Vlahov, G.; Anglani, C.; Murelli, C. Epicuticular wax of olive leaves. Phvtochemistrv 1992, 32, 49-52.

(19) Vlahov, G.; Rinaldi, G.; Del Re, P.; Giuliani, A. A. ${ }^{13} \mathrm{C}$ nuclear magnetic resonance spectroscopy for determining the different components of epicuticular waxes of olive fruit (Olea europaea) Dritta cultivar. Anal. Chim. Acta 2008, 624, 184-194.

(20) Vichi, S.; Cortés-Francisco, N.; Romero, A.; Caixach, J. Direct chemical profiling of olive (Olea europaea) fruit epicuticular waxes by direct electrospray-ultrahigh resolution mass spectrometry. J. Mass Spectrom. 2015, 50, 558-566. 
(21) Vichi, S.; Cortés-Francisco, N.; Caixach, J.; Barrios, G.; Mateu, J.; Ninot, A.; Romero, A. Epicuticular wax in developing olives (Olea europaea) is highly dependent on cultivar and fruit ripeness. L.Agric. Food Chem. 2016, 64, 5985-5994.

(22) Schönherr, J.; Riederer, M. Plant cuticles sorb lipophilic compounds during enzymatic isolation. Plant Cell Environ. 1986, 9, 459-466.

(23) Nobel, P. S. Physicochemical and environmental plant physiology, 4th edn. Oxford: Academic Press. 2009.

(24) Burghardt, M.; Riederer, M. Ecophysiological relevance of cuticular transpiration of deciduous and evergreen plants in relation to stomatal closure and leaf water potential. $J$. Exp. Bot. 2003, 54, 1941-1949.

(25) Peschel, S.; Franke, R.; Schreiber, L.; Knoche, M. Composition of the cuticle of developing sweet cherry fruit. Phvtochemistrv 2007, 68, 1017-1025.

(26) Järvinen, R.; Kaimainen, M.; Kallio, H. Cutin composition of selected northern berries and seeds. Food Chem. 2010, 122, 137-144.

(27) Parsons, E. P.; Popopvsky, S.; Lohrey, G. T.; Alkalai-Tuvia, S.; Perzelan, Y.; Bosland, P.; Bebeli, P. J.; Paran, I.; Fallik, E.; Jenks, M. A. Fruit cuticle lipid composition and water loss in a diverse collection of pepper (Capsicum). Phvsiol.Plant 2013, 149, 160-174.

(28) Leide, J.; Hildebrandt, U.; Reussing, K.; Riederer, M.; Vogg, G. The developmental pattern of tomato fruit wax accumulation and its impact on cuticular transpiration barrier properties: effects of a deficiency in a $\beta$-ketoacyl-coenzyme A synthase (LeCER6). Plant Physiol. 2007, 144, 1667-1679.

(29) Kosma, D. K.; Parsons, E. P.; Isaacson, T.; Lü, S.; Rose, J. K.; Jenks, M. A. Fruit cuticle lipid composition during development in tomato ripening mutants. Physiol. Plant 2009, 139, 107-117.

(30) Holloway, P. J.; Deas, A. H. B. Epoxyoctadecanoic acids in plant cutins and suberins. Phvtochemistrv 1973, 12, 1721-1735. 
(31) Riederer, M.; Schönherr, J. Covalent binding of chlorophenoxyacetic acids to plant cuticles. Arch. Environ. Contam. Toxicol. 1986, 15, 97-105.

(32) Holloway, P. J. The chemical constitution of plant cutins. In The plant cuticle. Cutler, D. F.; Alvin, K. L.; Price, C. E., Eds.; Academic Press, London, UK, 1982, pp 45-85.

(33) Ismail, H. M.; Brown, G. A.; Tucknott, O. G., Holloway, P. J.; Williams, A. A. Nonanal in epicuticular wax of golden egg plums (Prunus domestica). Phvtochemistrv 1977, 16, 769770.

(34) Szakiel, A.; Pączkowski, C.; Huttunen, S. Triterpenoid content of berries and leaves of bilberry Vaccinium myrtillus from Finland and Poland. J. Agric. Food Chem. 2012, 60, 11839-11849.

(35) Possingham, J. V.; Chambers, T. C.; Radler, F.; Grncarevic, M. Cuticular transpiration and wax structure and composition of leaves and fruit of Vitis vinifera. Aust. J. Biol. Sci. 1967, $20,1149-1154$.

(36) Zhang, Y.; Jayaprakasam, B.; Seeram, N. P.; Olson, L. K.; DeWitt, D.; Nair, M. G. Insulin secretion and cyclooxygenase enzyme inhibition by cabernet sauvignon grape skin compounds. L.Agric. Food Chem. 2004, 52, 228-233.

(37) Pensec, F.; Pączkowski, C.; Grabarczyk, M.; Woźniak, A.; Bénard-Gellon, M.; Bertsch, C.; Chong, J.; Szakiel, A. Changes in the triterpenoid content of cuticular waxes during fruit ripening of eight grape (Vitis vinifera) cultivars grown in the Upper Rhine Valley. J. Agric. Eood Chem. 2014, 62, 7998-8007.

(38) Poynter, J. G.; Farrimond, P.; Robinson, N.; Eglinton, G. Aeolian-derived higher plant lipids in the marine sedimentary record: Links with palaeoclimate. In Paleoclimatology and paleometeorology: modern and past patterns of global atmospheric transport. Leinen, M.; Sarnthein, M., Eds., Springer, Netherlands, 1989, pp 435-462.

(39) Kolattukudy, P. E. Plant waxes. Lipids 1970, 5, 259-275. 
(40) Buschhaus, C.; Herz, H.; Jetter, R. Chemical composition of the epicuticular and intracuticular wax layers on the adaxial side of Ligustrum vulgare leaves. New Phytol. 2007, $176,311-316$.

(41) Guo, S.; Duan, J. A.; Tang, Y. P.; Yang, N. Y.; Qian, D. W.; Su, S. L.; Shang, E. X. Characterization of triterpenic acids in fruits of Ziziphus species by HPLC-ELSD-MS. J. Agric. Food Chem. 2010, 58, 6285-6289.

(42) Guo, Q. L.; Gao, J. Y.; Yang, J. S. Analysis of bioactive triterpenes from Rubus chingii by cyclodextrin-modified capillary electrophoresis. Chroma. 2005, 62, 145-150.

(43) He, X.; Liu, R. H. Triterpenoids isolated from apple peels have potent antiproliferative activity and may be partially responsible for apple's anticancer activity. J. Agric. Food Chem. 2007, 55, 4366-4370.

(44) Jäger, S.; Trojan, H.; Kopp, T.; Laszczyk, M. N.; Scheffler, A. Pentacyclic triterpene distribution in various plants-rich sources for a new group of multi-potent plant extracts. Molecules 2009, 14, 2016-2031.

(45) Schreiber, L.; Riederer, M. Ecophysiology of cuticular transpiration: comparative investigation of cuticular water permeability of plant species from different habitats. Oecologia 1996, 107, 426-432.

(46) Schreiber, L.; Elshatshat, S.; Koch, K.; Lin, J.; Santrucek, J. AgCl precipitates in isolated cuticular membranes reduce rates of cuticular transpiration. Planta 2006, 223, 283-290.

(47) Fich, E. A.; Segerson, N. A.; Rose, J. K. The plant polyester cutin: biosynthesis, structure, and biological roles. Ann. Rev. Plant Biol. 2016, 67, 207-233.

(48) Vogg, G.; Fischer, S.; Leide, J.; Emmanuel, E.; Jetter, R.; Levy, A. A.; Riederer, M. Tomato fruit cuticular waxes and their effects on transpiration barrier properties: functional characterization of a mutant deficient in a very-long-chain fatty acid $\beta$-ketoacyl-CoA synthase. J.Exp. Bot. 2004, 55, 1401-1410. 
(49) Buschhaus, C.; Jetter, R. Composition and physiological function of the wax layers coating Arabidopsis leaves: $\beta$-amyrin negatively affects the intracuticular water barrier. Plant Physiol. 2012, 160, 1120-1129.

(50) Riederer, M.; Schneider, G. The effect of the environment on the permeability and composition of Citrus leaf cuticles. Planta 1990, 180, 154-165.

(51) Lasoski, S. W.; Cobbs, W. H. Moisture permeability of polymers. I. Role of crystallinity and orientation. L.Polvm.Sci. 1959, 36, 21-33. 


\section{Figure Legends}

Figure 1. The total amount of cutin monomers (a) and the total amount of cuticular waxes (b) for the three developmental stages of Olea europaea L. cultivar 'Arbequina' fruits (green, turning and black) and the adaxial leaf surface $(n=5)$.

There were no statistical differences between the three fruit stages $(p=0.074$ and $p=0.565$ for cutin and wax respectively). The leaf cutin monomer amount was significantly lower ( $\mathrm{p}$ $0.001)$ and the leaf total cuticular wax amount was significantly higher $(\mathrm{p}<0.001)$ in comparison to the fruit (black stage).

Figure 2. Surface area (a) and the permeance for water (b) of Olea europaea L. cultivar 'Arbequina' fruits (green, turning and black) and the adaxial leaf surface of fully expanded leaves $(n=12)$.

The surface area of the three fruit stages differed significantly $(\mathrm{p}<0.001$, green and turning $\mathrm{p}$ $<0.001$, green and black $\mathrm{p}<0.001$, turning and black $\mathrm{p}=0.051$ ). The water permeances of the fruit stages did not differ significantly $(\mathrm{p}=0.187)$. The water permeance of the adaxial leaf surface was significantly lower than the water permeance of the black-stage fruits $(p<$ $0.01)$ 
Table 1. Composition of the cutin polymer of Olea europaea L. cultivar 'Arbequina' fruits in green, turning and black stages and the fully expanded, adaxial leaf surface. Data were given as means \pm standard deviations $\left(\mu \mathrm{g} \mathrm{cm}^{-2} ; \mathrm{n}=5\right)$.

\begin{tabular}{|c|c|c|c|c|c|c|c|c|c|c|c|c|}
\hline \multirow{3}{*}{$\begin{array}{l}\text { compound classes } \\
\text { fatty acids }\end{array}$} & \multicolumn{9}{|c|}{ fruit } & \multirow{2}{*}{\multicolumn{3}{|c|}{$\frac{\text { leaf }}{\text { adaxial surface }}$}} \\
\hline & \multicolumn{3}{|c|}{ green stage } & \multicolumn{3}{|c|}{ turning stage } & \multicolumn{3}{|c|}{ black stage } & & & \\
\hline & 17.92 & \pm & 2.47 & 19.21 & \pm & 1.99 & 32.06 & \pm & 11.34 & 11.68 & \pm & 3.93 \\
\hline$\omega$-hydroxy fatty acids & 46.09 & \pm & 11.91 & 49.56 & \pm & 9.34 & 96.30 & \pm & 31.42 & 13.56 & \pm & 2.26 \\
\hline$\omega$-hydroxy fatty acids with mid-chain hydroxy group & 698.90 & \pm & 43.17 & 742.11 & \pm & 60.68 & 864.72 & \pm & 143.71 & 273.03 & \pm & 39.28 \\
\hline$\omega$-hydroxy fatty acids with mid-chain epoxy group & & - & & & - & & & - & & 247.36 & \pm & 40.68 \\
\hline$\omega$-hydroxy fatty acids with mid-chain oxo group & 11.09 & \pm & 9.74 & 5.60 & \pm & 2.93 & 5.85 & \pm & 2.53 & & - & \\
\hline$\alpha, \omega$-dicarboxylic fatty acids & 1.38 & \pm & 0.25 & 2.91 & \pm & 2.10 & 1.70 & \pm & 0.28 & & - & \\
\hline$\alpha, \omega$-dicarboxylic fatty acids with mid-chain epoxy group & 9.61 & \pm & 3.69 & 7.26 & \pm & 4.53 & 5.81 & \pm & 2.47 & 3.66 & \pm & 0.60 \\
\hline phenolic compounds & 46.61 & \pm & 5.14 & 44.19 & \pm & 5.54 & 42.39 & \pm & 4.53 & 2.55 & \pm & 0.58 \\
\hline not identified & 137.68 & \pm & 13.96 & 134.10 & \pm & 16.08 & 106.29 & \pm & 13.12 & 78.62 & \pm & 11.12 \\
\hline total cutin & 969.29 & \pm & 54.10 & 1004.94 & \pm & 71.42 & 1129.05 & \pm & 151.04 & 630.46 & \pm & 88.57 \\
\hline
\end{tabular}


Table 2. Composition of the cuticular waxes of Olea europaea L. cultivar 'Arbequina' fruits in green, turning and black stages and the fully expanded adaxial leaf surface. Data were given as means \pm standard deviations $\left(\mu \mathrm{g} \mathrm{cm}^{-2} ; \mathrm{n}=5\right)$.

\begin{tabular}{|c|c|c|c|c|c|c|c|c|c|c|c|}
\hline \multirow{3}{*}{$\begin{array}{l}\text { compound classes } \\
\text { fatty acids }\end{array}$} & \multicolumn{8}{|c|}{ fruit } & \multirow{2}{*}{\multicolumn{3}{|c|}{$\begin{array}{c}\text { leaf } \\
\text { adaxial surface }\end{array}$}} \\
\hline & \multicolumn{2}{|c|}{ green stage } & \multicolumn{3}{|c|}{ turning stage } & \multicolumn{3}{|c|}{ black stage } & & & \\
\hline & $15.23 \pm$ & 2.50 & 18.60 & \pm & 2.48 & 18.62 & \pm & 1.60 & 2.14 & \pm & 0.64 \\
\hline primary alcohols & $17.86 \pm$ & 2.16 & 21.43 & \pm & 2.07 & 23.4 & \pm & 2.27 & 0.25 & \pm & 0.05 \\
\hline aldehydes & $3.19 \pm$ & 0.79 & 4.67 & \pm & 0.66 & 4.55 & \pm & 0.94 & & - & \\
\hline$n$-alkanes & $1.12 \pm$ & 0.22 & 2.27 & \pm & 0.68 & 3.23 & \pm & 0.84 & 8.47 & \pm & 3.09 \\
\hline alkyl esters & $0.53 \pm$ & 0.13 & 3.77 & \pm & 1.32 & 8.60 & \pm & 3.00 & & - & \\
\hline methyl esters & $0.10 \pm$ & 0.02 & 0.20 & \pm & 0.03 & 0.17 & \pm & 0.09 & & - & \\
\hline phenyl methyl esters & $0.55 \pm$ & 0.23 & 1.24 & \pm & 0.28 & 1.41 & \pm & 0.50 & & - & \\
\hline diacylglycerols & $0.82 \pm$ & 0.26 & 1.71 & \pm & 0.48 & 2.98 & \pm & 0.62 & & - & \\
\hline triterpenoids & $144.45 \pm$ & 19.43 & 135.82 & \pm & 12.97 & 129.19 & \pm & 12.18 & 266.36 & \pm & 38.97 \\
\hline sterols & $0.08 \pm$ & 0.04 & 0.06 & \pm & 0.03 & 0.08 & \pm & 0.03 & & - & \\
\hline not identified & $10.69 \pm$ & 3.82 & 11.84 & \pm & 2.97 & 16.41 & \pm & 1.92 & 43.19 & \pm & 13.71 \\
\hline total wax & $194.61 \pm$ & 22.84 & 201.61 & \pm & 19.65 & 208.64 & \pm & 17.94 & 320.41 & \pm & 39.54 \\
\hline
\end{tabular}


Table 3. Amount of cyclic and very-long-chain acyclic wax fractions $\left(\mu \mathrm{g} \mathrm{cm}{ }^{-2}\right.$ ), weighted average chain length (ACL) of the very-long-chain acyclic wax fraction, ratio of cuticular waxes and cutin, ratio of main cutin monomers of $\mathrm{C}_{16}$ and $\mathrm{C}_{18}$ of Olea europaea $\mathrm{L}$. cultivar 'Arbequina' fruits in green, turning and black stages and the fully expanded adaxial leaf surface. Data were given as means \pm standard deviations ( $\mathrm{n}=5$ ).

\begin{tabular}{|c|c|c|c|c|c|c|c|c|c|c|c|c|c|c|c|c|}
\hline \multirow{2}{*}{$\begin{array}{l}\text { organ } \\
\text { fruit }\end{array}$} & \multirow[b]{2}{*}{ green stage } & \multicolumn{3}{|c|}{ cyclic fraction } & \multicolumn{3}{|c|}{ very-long-chain acyclic fraction } & \multicolumn{3}{|c|}{$\mathbf{A C L}$} & \multicolumn{3}{|c|}{ wax/cutin } & \multicolumn{3}{|c|}{$\mathrm{C}_{16} / \mathrm{C}_{18}$} \\
\hline & & 145.07 & \pm & 19.31 & 38.85 & \pm & 5.26 & 25.80 & \pm & 0.11 & 0.20 & \pm & 0.03 & 1.10 & \pm & 0.11 \\
\hline & turning stage & 137.12 & \pm & 13.07 & 52.65 & \pm & 6.18 & 26.55 & & 0.19 & 0.20 & \pm & 0.03 & 1.06 & \pm & 0.12 \\
\hline & black stage & 130.68 & \pm & 12.09 & 61.55 & \pm & 5.94 & 27.27 & & 0.26 & 0.19 & \pm & 0.03 & 0.78 & \pm & 0.17 \\
\hline leaf & leaf adaxial & 266.36 & \pm & 38.97 & 10.86 & \pm & 3.51 & 30.06 & $\perp$ & 0.27 & 0.52 & \pm & 0.07 & 0.45 & \pm & 0.02 \\
\hline
\end{tabular}


Figure 1.

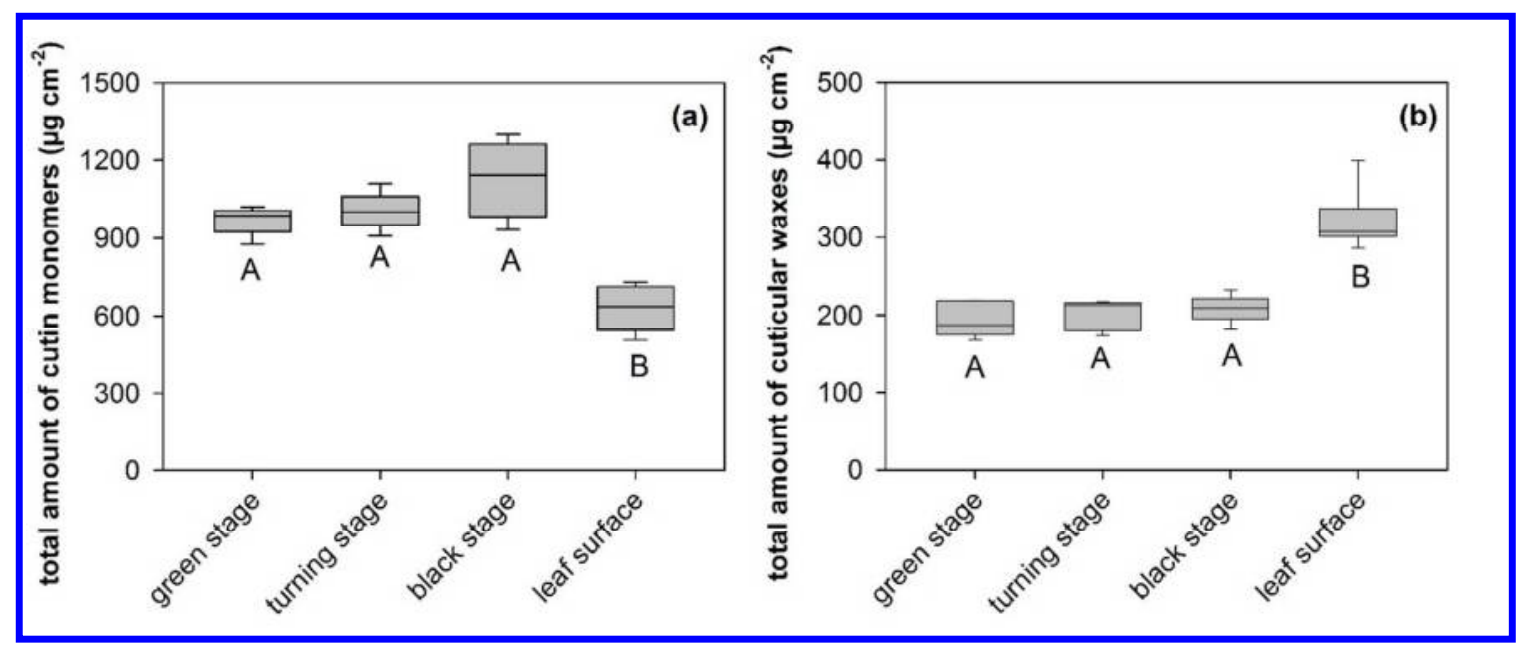


Figure 2.

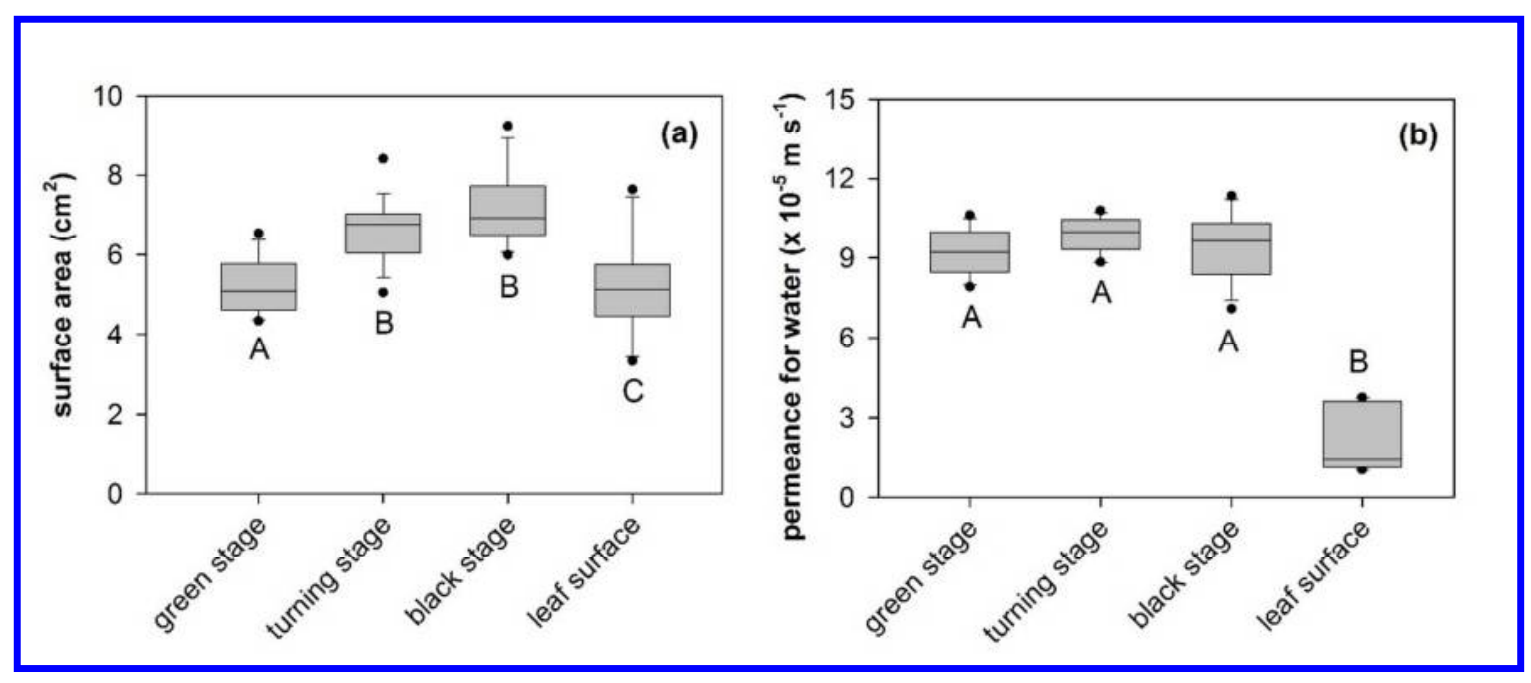


TOC graphic

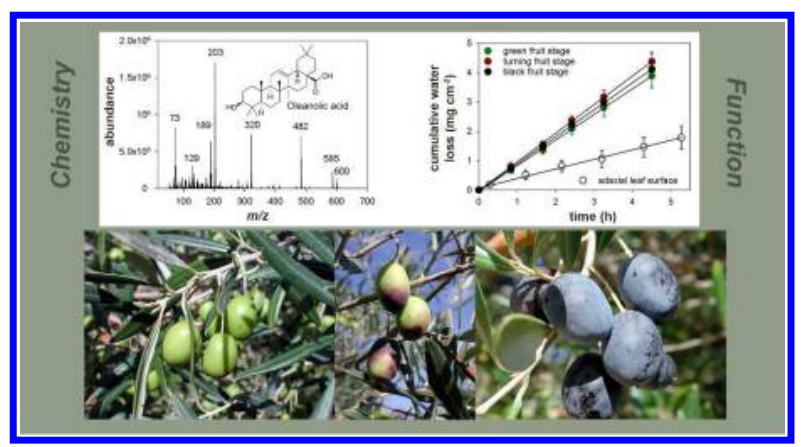

